\title{
A new genus and species of Dictyopharidae (Homoptera) from Rovno and Baltic amber based on nymphs
}

\author{
Alexander F. Emeljanov ${ }^{1, \dagger}$, Dmitry E. Shcherbakov ${ }^{2, \ddagger}$ \\ I Zoological Institute, Russian Academy of Sciences, Universitetskaya Emb. 1, St. Petersburg, 199034 Russia \\ 2 Borissiak Paleontological Institute, Russian Academy of Sciences, Profsoyuznaya St. 123, Moscow, 117997 \\ Russia \\ † urn:lsid:zoobank.org:author:130C840D-15B2-4C4F-A74E-986E0019714E \\ † urn:lsid:zoobank.org:author:64F1D8C2-15EF-4C61-B15F-9960E7156BFF \\ Corresponding author: Dmitry E. Shcherbakov (dshh@narod.ru) \\ Academic editor: Michael Engel | Received 3 July 2011 | Accepted 8 August 2011 | Published 24 September 2011 \\ urn:lsid:zoobank.org:pub:7DECCF17-9573-49F6-9EDA-363EB18F2E80 \\ Citation: Emeljanov AF, Shcherbakov DE (2011) A new genus and species of Dictyopharidae (Homoptera) from Rovno \\ and Baltic amber based on nymphs. In: Shcherbakov DE, Engel MS, Sharkey MJ (Eds) Advances in the Systematics of \\ Fossil and Modern Insects: Honouring Alexandr Rasnitsyn. ZooKeys 130: 175-184. doi: 10.3897/zookeys.130.1775
}

\begin{abstract}
Alicodoxa rasnitsyni gen. et sp. n. (Dictyopharinae: Orthopagini) is described based on a nymph from Rovno amber; it also occurs in Baltic amber. A small additional wax plate dorsal to the large wax plate of abdominal tergites VI-VIII is first reported in this and other genera of Dictyopharidae. A lectotype is designated for Pseudophana reticulata Germar \& Berendt, 1856 transferred to Protepiptera (Achilidae): Protepiptera reticulata (Germar \& Berendt, 1856), comb. n.
\end{abstract}

\section{Keywords}

Fulgoroidea, planthoppers, Dictyopharinae, Orthopagini, Achilidae, fossil, Baltic amber, Eocene, morphology, wax plates

\section{Introduction}

The family Dictyopharidae is poorly represented in the fossil record. Its oldest member, described from the Upper Cretaceous (Santonian) of Taimyr, has been assigned to the

Copyright A.F. Emeljanov, D.E. Shcherbakov. This is an open access article distributed under the terms of the Creative Commons Attribution License, which permits unrestricted use, distribution, and reproduction in any medium, provided the original author and source are credited. 
extinct tribe Netutelini (Emeljanov 1983). Several Cenozoic genera have been attributed to the family, but most of them need re-examination to determine their systematic position in more detail (see Szwedo et al. 2004, Szwedo 2008). Recently, Szwedo (2008) described a new monotypic genus from Baltic amber and placed it in a tribe of its own, Worskaitini, which he considered closely related to Netutelini.

Two nymphs from Late Eocene Baltic amber were described by Germar and Berendt (1856) as Pseudophana reticulata, i.e. as Dictyopharidae in the modern sense (Dictyophara Germar $=$ Pseudophana Burmeister). Based on the original illustrations, these two specimens have been reinterpreted by Emeljanov (1983), the 3rd instar as resembling Tropiduchidae, and the late instar ("pupa") as belonging to Achilidae, most probably to the extant genus Cixidia Fieber. The late instar nymph (designated below as the lectotype of $P$. reticulata) indeed seems to be an achilid and presumably belongs to the extinct genus Protepiptera Usinger, which is similar to Cixidia, whereas the 3rd instar nymph is a dictyopharid. A photograph of yet another 3rd instar nymph of Dictyopharidae from Baltic amber has been published by Weitschat and Wichard (1998: pl. 46a). These two dictyopharid nymphs are conspecific with an excellently preserved nymph from Rovno amber, described below as a new genus and species and placed with substantial certainty into the extant tribe Orthopagini.

The Rovno amber from NW Ukraine is roughly contemporaneous to Baltic amber, both Late Eocene in age and containing similar but distinct insect faunas with many species in common (Perkovsky et al. 2010). The second planthopper species shared between the two ambers is Protepiptera kaweckii Usinger, 1939 (Achilini s.l.), the commonest Baltic amber achilid (redescribed by Emeljanov and Shcherbakov 2009). Other planthopper families recorded from Rovno amber are Tropiduchidae (Perkovsky and Bodgasarov 2009) and Cixiidae.

\section{Material and methods}

The specimen was collected in Klesov, Rovno Region, Ukraine, and deposited in the amber collection of the Schmalhausen Institute of Zoology, National Academy of Sciences of Ukraine, Kiev (SIZK). Morphological terminology follows Emeljanov (1993, 1994). Photographs were taken with Leica MZ9.5 stereomicroscope and Leica DFC420 camera and post-processed using Helicon Focus software. 


\section{Taxonomy}

Superfamily Fulgoroidea Latreille, 1807

Family Achilidae Stål, 1866

Tribe Achilini Stål, 1866, s.l.

Genus Protepiptera Usinger, 1939

Protepiptera reticulata (Germar \& Berendt, 1856), comb. n. http://species-id.net/wiki/Protepiptera_reticulata

Pseudophana reticulata Germar \& Berendt, 1856: 16, pl. II, fig. 4b (pars)

Dictyophara reticulata (Germar \& Berendt, 1856): Metcalf and Wade 1966: 126

Cixidia reticulata (Germar \& Berendt, 1856): Szwedo et al. 2004: 85

Lectotype. Late instar nymph ("pupa") in Baltic amber, former East Prussia (Germar and Berendt 1856: 16, pl. II, fig. 4b), designated here.

Remarks. Of the two syntype nymphs, the late instar is selected as a lectotype. The 3 rd instar nymph, belonging to Dictyopharinae, is discussed under the new genus and species below. According to Szwedo et al. (2004), the type material was probably lost during World War II.

This species is possibly a senior synonym of $P$. kaweckii Usinger, 1939 based on adults and very common in Baltic amber. Other possible senior synonyms of $P$. kaweckii are "Cixius" longirostris Germar et Berendt, 1856 and "Oliarus" oligocenus Cockerell, 1910 (Emeljanov and Shcherbakov 2009).

\section{Family Dictyopharidae Spinola, 1839}

Subfamily Dictyopharinae Spinola, 1839

Tribe Orthopagini Emeljanov, 1983

\section{Genus Alicodoxa gen. n.}

urn:Isid:zoobank.org:act:C730EB51-0600-45A1-8E17-993E07139A32

http://species-id.net/wiki/Alicodoxa

\section{Type species. Alicodoxa rasnitsyni sp. n.}

Etymology. The genus and the type species are named in honour of our friend and colleague Prof. Alexandr Rasnitsyn. The grammatical gender is feminine.

Diagnosis. Metope not visible in dorsal aspect. Coryphe $1 / 3$ longer than pronotal disc along midline. Pronotum deeply angulately emarginate posteriorly. Lateral carinae of mesonotal disc anteriorly converging at acute angle. Fore femur without subapical tooth. Abdominal tergites IV-V with 1-2 sensory pits displaced forwards from the row of pits. Tergites VI-VII with 2 medial and 2-3 lateral pits. Tergites VI-VIII with large lower and small upper wax plates, upper plate of tergite VII subdivided. 
Remarks. Similar to the extant genera Orthopagus Uhler and Saigona Matsumura, but in the nymphs of these latter the metope is visible from above, coryphe longer relative to pronotal disc, pronotum less emarginate posteriorly, and tergites VI-VII with 4 medial and 1-0 lateral pits. Subdivided upper wax plate of tergite VII is unknown in other Dictyopharidae. Other characters listed under Diagnosis assign the new genus to Orthopagini within Dictyopharinae (see Discussion).

\section{Alicodoxa rasnitsyni sp. $\mathrm{n}$.}

urn:Isid:zoobank.org:act:F0581436-F029-46E3-9229-29D20AFF5140

http://species-id.net/wiki/Alicodoxa_rasnitsyni

Figs $1-5$

Material. Holotype, 4th instar nymph, SIZK K-3719, Klesov, Rovno amber, Ukraine; Late Eocene. Syninclusions: Mycetophilidae, Sciaroidea, Symphypleona, Acari, stellate hairs. Petaloid blind fissures arising all around lateral margins of the nymph and directed nearly laterad completely separate its dorsal and ventral sides so that only parts of its mid and hind legs are visible from above. The ventral aspect is mostly masked with variously directed fissures and in some places with milky impurities.

Description. Nymph dark brown, ovoid, moderately elongate, $4.1 \mathrm{~mm}$ long, 2.2 $\mathrm{mm}$ wide; head projecting forwards beyond oval contour; dorsum finely transversely shagreened. Coryphe somewhat longer than wide; its lateral and anterior margins forming regular parabola; its posterior margin very shallowly concave, situated at about eye midlength in dorsal aspect. All carinae of coryphe, including posterior one and medial one, well developed. Metope (only partly visible) with medial areas somewhat widened at head apex; lateral areas with two rows of sensory pits, with an additional row of four smaller pits in between the two rows. Rostrum reaching beyond hind coxae, apical segment shorter than subapical one.

Pronotal disc strongly projecting forwards ( $2 / 3$ of its median length situated anterior to level of posterior eye margins), its anterior margin truncate, almost straight, anterolateral angles rounded, lateral margins moderately diverging backwards. Posterior margin of pronotum with deep right-angled emargination reaching almost $1 / 3$ of pronotal disc length. Pronotal disc slightly narrower and $1 / 4$ shorter along midline than coryphe, bordered with distinct carinae along all free margins, medial carina also distinct, but posterolateral carinae undeveloped, and boundary between disc and lateral lobes traceable only as flexure of surface plane (posterior ends of these flexures close to points where lateral carinae of mesonotal disc approach pronotal margin). Sensory pits of pronotal disc and paradiscal areas forming one entity: disc with row of 4 large pits along lateral margin and 3 smaller pits in second, more medial row; paradiscal area with 6 large pits in marginal row (indistinctly subdivided into two groups, each with 3 pits) and 8-10 smaller pits in second row. Humeral area with 3 pits in main row and 1 additional pit; pectoral group of pits (about 7 in two tangled rows) situated as is usual in the family near posterior margin of paranotal lobe. Lateral and collateral carinae distinct. Mesonotal disc 


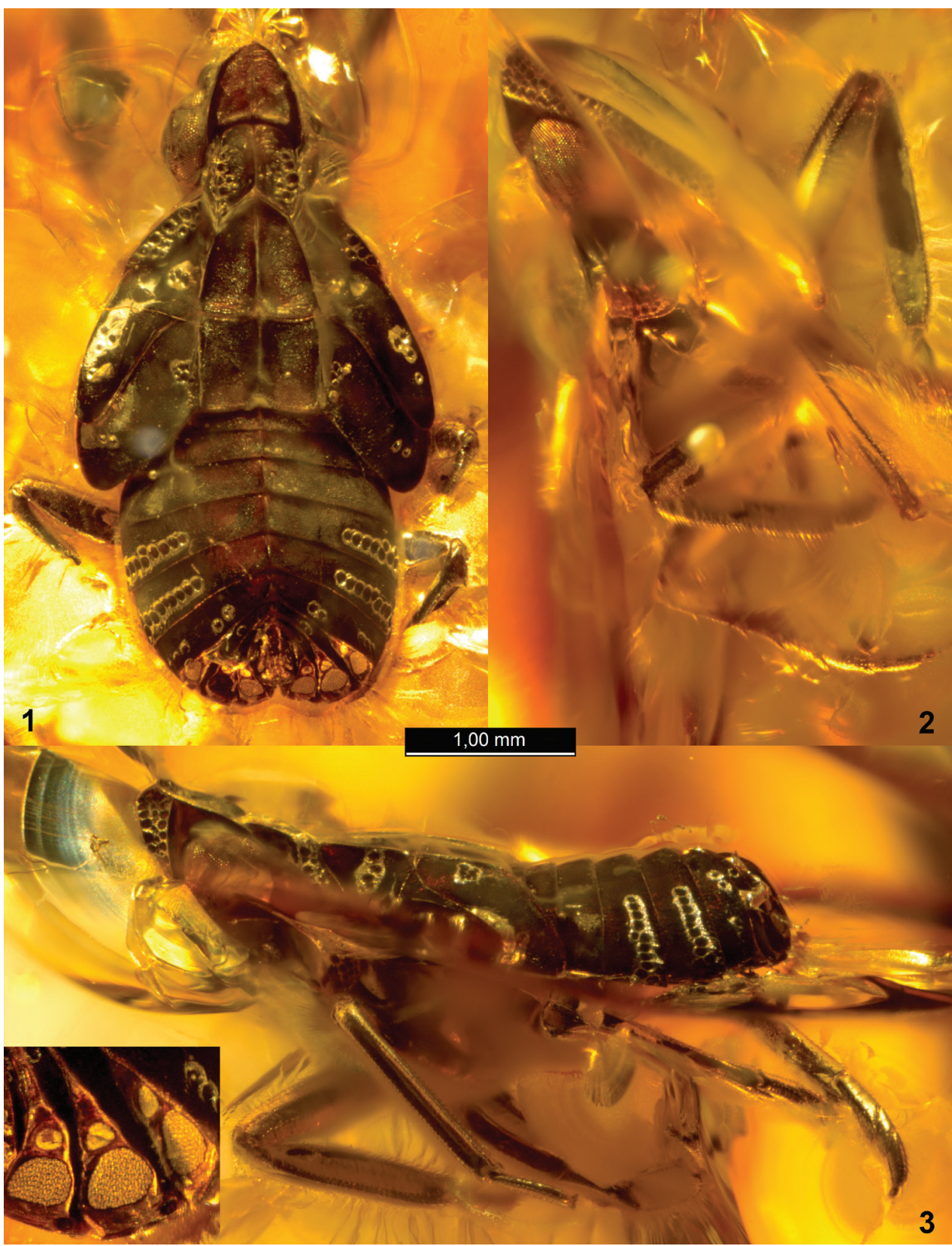

Figures I-3. Alicodoxa rasnitsyni gen. et sp. n. (Orthopagini), 4th instar nymph, Rovno amber: I dorsal view $\mathbf{2}$ anteroventral view $\mathbf{3}$ lateral view (all to same scale); inset, wax plates of the right side, enlarged.

arrow-shaped anteriorly (its lateral carinae anteriorly converging at nearly acute angle, running parallel to posterior pronotal margin). Group of 6-7 pits ( 3 medial pits larger) situated laterad of lateral carinae. Fore wing pads mediad of subcostal carina with 3 pits (in triangle) in middle part and 1 pit near apex, and in costal area with 2 pits in middle 

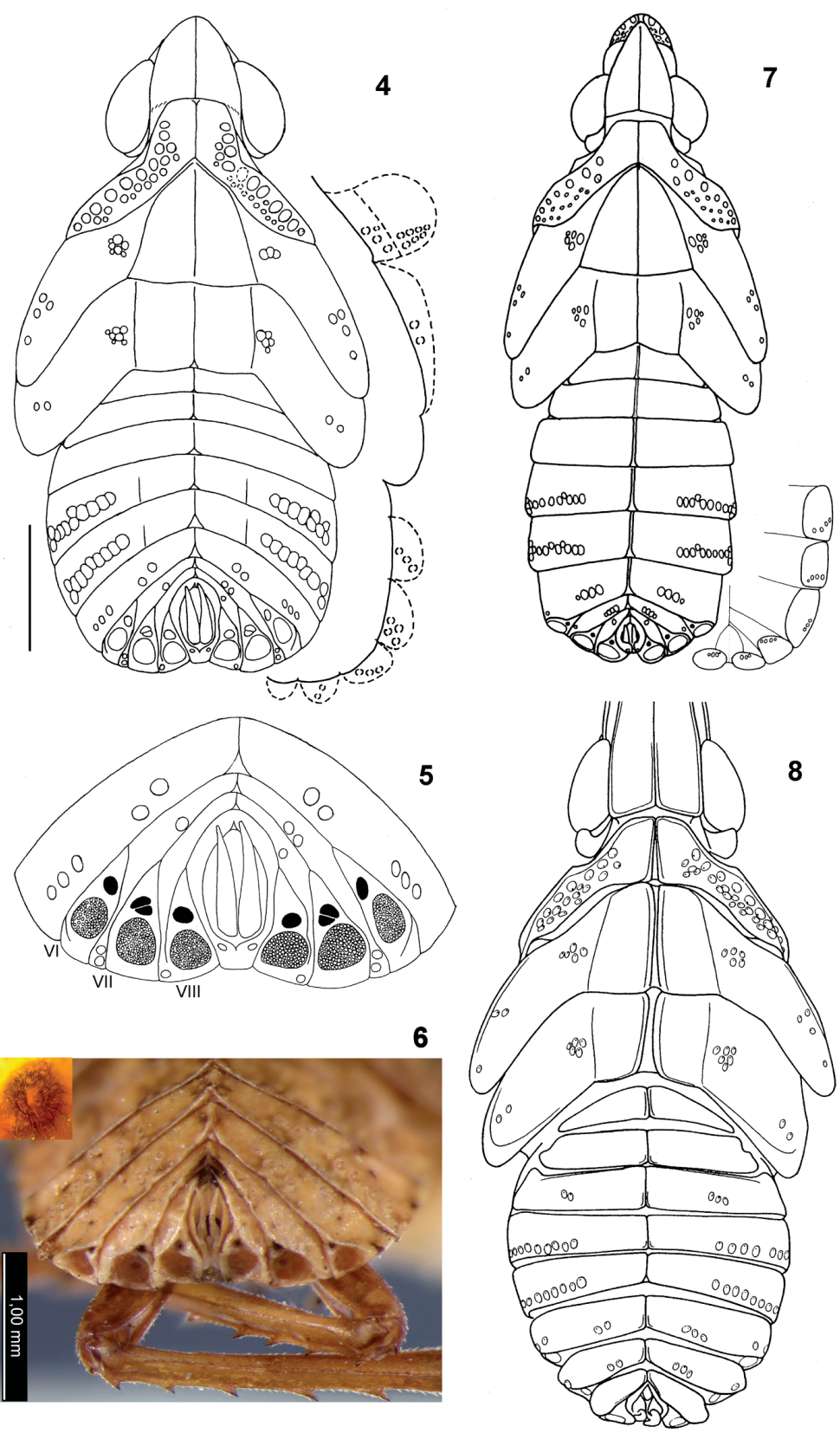

Figures 4-8. 4-5 Alicodoxa rasnitsyni gen. et sp. n., 4th instar nymph, Rovno amber: 4 dorsal view, slightly corrected and schematized; on the right, arrangement of sensory pits on the lateral body parts facing ventrad (scale bar, $1 \mathrm{~mm}$ ) $\mathbf{5}$ posterior part of the abdomen, arrangement of wax plates and sensory pits; 6-7 Saigona ussuriensis (Lethierry) (Orthopagini), nymphs, recent: 6 5th instar, posterior part of the abdomen with wax plates; inset, upper wax plate of segment VIII, enlarged 7 4th instar, dorsal view; on the right, arrangement of sensory pits on ventrolateral parts of the tergites; 8 Dictyophara pannonica (Germar), 4th instar nymph, recent, dorsal view (apical part of the head not shown; after Emeljanov 1994). 
part (against group of 3 pits). Posterior margins of fore and hind wing pads subparallel, directed obliquely posterolaterad. Metanotal disc rectangular, about 1.3 times as wide as long, with all carinae distinct. Medial group of pits laterad of disc similar to that on mesonotum; hind wing pad subapically with 2 pits in oblique row subparallel to posterior pad margin. Fore legs slightly widened, as long as mid legs. Fore femora without subapical tooth on posteroventral carina. Fore tibiae slightly flattened, lanceolate, widest about midlength. Mid tibiae not widened, relatively slender. Hind tibiae with 5 lateral spines including knee spine; apical teeth not possible to count. Hind tarsus three-segmented.

Abdomen with well developed middorsal carina, indistinct intermediate carinae on tergites IV-V, without sublateral carinae. Tergites I-III without pits; tergites IV-V with long (complete) rows of $8-10$ pits, 5 th or 6 th pit (from body midline) displaced anteriad (sometimes there are 2 such pits, forming rudimentary second row anteriorly - see Fig. 1). Lateral areas of tergites IV-V with 3-4 pits in row or group. Tergites VIVIII with several pits displaced medially (2 pits on VI, 2 pits on VII, $0-1$ pit on VIII - absent at one side) and several pits laterally (ventrally: 3 pits on VI, 2 pits on VII, 1 pit on VIII). Lateral area with 3 pits on tergite VI, 2 pits on tergite VII, and 1 pit on tergite VIII. Tergite IX ventrally with pair of pits (1 pit at each side).

Wax plates situated in subtriangular posterolateral areas of tergites VI-VIII, separated from rest of tergite by carina and facing posteriad. Wax plates of uniform structure: large rounded lower (lateral) plate with discernible circular wax gland pores and small adjacent upper (medial) plate. Small upper wax plate on tergite VII subdivided, crossed by narrow chitinous bridge nearly perpendicular to body sagittal plane.

Remarks. The three-segmented hind tarsus in the holotype of $A$. rasnitsyni sp. n. indicates the 4 th or 5 th instar, while the fore wing pads not nearly reaching the apices of hind wing pads suggest the 4th instar (or 5 th instar of a brachypterous planthopper, but the latter is not consistent with the presence of well developed abdominal wax plates).

In the nymphs of Dictyopharinae posterolateral carinae of the pronotal disc are usually absent, as in the new genus, and sensory pits of the second row are arranged more or less evenly across the imaginary boundary between pronotal disc and paradiscal area, though their number is not the same at the left and right sides.

The 3rd instar nymph from Baltic amber illustrated by Weitschat and Wichard (1998: pl. 46a) agrees with the holotype of $A$. rasnitsyni sp. n. in all diagnostic characters. The original drawing of the 3 rd instar nymph of „Pseudophana reticulata”(Germar and Berendt 1856: pl. II, fig. 4a) is inaccurate, e.g. the legs are shown too short and the sensory pits on the fore wing pad too numerous. Nevertheless, several salient features allow recognizing it as conspecific with the holotype of the new species. Therefore, $A$. rasnitsyni sp. $\mathrm{n}$. is recorded from both Baltic and Rovno amber.

\section{Discussion}

Alicodoxa gen. $\mathrm{n}$. is a typical member of Dictyopharinae in its general habitus and basic structural features. The subfamily assignment is confirmed by the presence of typical 
wax plates on the VI-VIII abdominal tergites (wax plates are undeveloped in another subfamily, Orgeriinae).

Nymphs of Dictyopharinae are rather uniform and difficult to identify, except for some aberrant forms. Nymphal characters to diagnose all the tribes have not been revealed yet, but there is a certain amount of morphological descriptions of varying accuracy and credibility (Wilson and McPherson 1981, Emeljanov 1993, 1994, Yang and Yeh 1994, McPherson and Wilson 1995). Several figures of nymphs in earlier papers (e.g. Sirrine and Fulton 1914, Logvinenko 1971) are not informative enough.

The descriptions scattered in the literature include those of nymphs (mainly of the last, 5th instar) from the tribes Dictyopharini, Orthopagini, Nersiini, Taosini, Phylloscelini, and Scoloptini. With the exception of Phylloscelini (genus Phylloscelis Germar), we examined nymphs from all these tribes plus the nymphs (yet undescribed) of the tribe Aluntiini, available in the collection of the Zoological Institute RAS. The nymphs of Lappidini, Capenini, Cleotychini, and Hastini remain unknown.

The wax plates of planthopper nymphs are originally confined to the abdominal tergites VI-VIII. The presence of 5 primary wax plates at each side of the tergites VIVIII is characteristic of all Fulgoroidea nymphs except the primitive family Cixiidae (Emeljanov 2009). In many families these plates are greatly modified and variously reduced, but in some Fulgoridae, Nogodinidae, Ricaniidae, Flatidae, and Hypochthonellidae a complete set of wax plates is retained on at least one segment.

Within Dictyopharidae (Dictyopharinae) the structure of wax plates is quite uniform, except for the wax plates of segment VI often being small (Dictyophara multireticulata Mulsant \& Rey) or absent (Nersia Stål, Scolops Schaum), but apparently only in the late instars (traced through developmental stages in Nersia: Wilson and McPherson 1981). In the holotype nymph of Alicodoxa rasnitsyni sp. n. a second, small, upper (medial) wax plate was discovered for the first time above the large, lower (lateral) one that was described in many genera (Wilson and McPherson 1981, Emeljanov 1990, 1993, Yang and Yeh 1994, McPherson and Wilson 1995). Subsequent examination has revealed the presence of the upper wax plates in nearly all the studied extant 5 th instar nymphs from various tribes of Dictyopharinae, especially large ones in the nymphs of Saigona ussuriensis (Lethierry) (Figs 6-7). In these latter, at high magnification the upper wax plates show numerous dark striae radiating from the pale centre (Fig. 6, inset), the fine structure very different from that of the lower wax plates covered with densely packed circular wax gland pores.

In Zanna tenebrosa (Fabricius) of the subfamily Zanninae, considered the least advanced in the family Fulgoridae (Emeljanov 1979, Urban and Cryan 2009), there is a complete set of 5 wax plates at each side of segments VI-VIII, and the lower (lateral) plates differ in their structure from the remaining, uniformly built ones. In other Fulgoridae studied there are only 2 wax plates and only on the segments VII-VIII (Wilson and Wheeler 1992, Yang and Yeh 1994; in the former paper, the "dark brown sclerite" dorsal to the wax plate is apparently the upper wax plate). The lower wax plate is apparently homologous in Fulgoridae and Dictyopharidae, whereas the upper wax plate could be homologized to the row of 4 upper wax plates reduced to a single plate. This suggestion is corroborated by the upper wax plate of segment VII being subdivided in A. rasnitsyni sp. $\mathrm{n}$. 
The new genus is assigned to the tribe Orthopagini based on the arrow-shaped anterior convergence of the lateral carinae of the mesonotal disc, combined with one or two sensory pits being displaced forwards from rows on the abdominal tergites IV-V; the latter character is found only in Orthopagini, the former also in Nersiini. The subapical tooth at the fore femur is characteristic of most Orthopagini but absent in several species of Centromeria Stål and in the new genus.

The tribe Orthopagini is presently distributed mainly in the Oriental and eastern Palearctic regions, plus three or four genera in the tropical Africa. The tribe Nersiini is Neotropical by origin and is confined to the New World (with only one subendemic genus, Rhynchomitra Fennah, in the Nearctic). Only the tribe Dictyopharini occurs now in Europe; in the nymphs of this tribe lateral carinae of the mesonotal disc are straight, not curved mediad, terminating separately at the anterior segment margin, and several pits on the abdominal tergites are displaced posteriad (not anteriad) from the row (Fig. 8).

The nymphs of Worskaitini are unknown; the adult of Worskaito stenexi Szwedo from Baltic amber differs from Alicodoxa gen. $n$. by the narrower, more elongate head. Because elongation of the head in Dictyopharinae, if it occurs, proceeds gradually from instar to instar, the head proportions of the 4th instar suggest that the head of adult $A$. rasnitsyni sp. n. must be short and broad.

\section{Acknowledgements}

We are deeply grateful to Dr. Evgeny Perkovsky (SIZK) for providing the specimen for study, to Dr. Roman Rakitov (PIN) for checking the English of the manuscript, and to two anonymous reviewers for valuable comments. The study was supported by the Russian Foundation for Basic Research grant 08-04-00134 and the Presidium of RAS program "Biosphere origin and evolution” (subprogram II).

\section{References}

Emeljanov AF (1979) The problem of family distinction between the Fulgoridae and the Dictyopharidae (Homoptera, Auchenorrhyncha). Trudy Zoologicheskogo instituta Akademii Nauk SSSR 82: 3-22 [in Russian]

Emeljanov AF (1983) Dictyopharidae from the Cretaceous deposits on the Taymyr Peninsula (Insecta, Homoptera). Paleontological Journal 17(3): 77-82.

Emeljanov AF (1993) Morphological peculiarities of the larvae of the family Dictyopharidae (Homoptera). I. General characteristic and a key to genera of the Palaearctic fauna. Entomologicheskoe Obozrenie 72: 794-812 [in Russian]

Emeljanov AF (1994) Morphological peculiarities of the larvae of the family Dictyopharidae (Homoptera). II. Developmental changes. Entomologicheskoe Obozrenie 73, 645-665 [in Russian].

Emeljanov AF (2009) Evolutionary transformations of abdominal wax-plates in the larvae of the Fulgoroidea (Homoptera, Cicadina). Entomological Review 89: 1035-1054. 
Emeljanov AF, Shcherbakov DE (2009) New planthoppers of the tribe Achilini (Homoptera, Fulgoroidea, Achilidae) from Baltic amber. Paleontological Journal 43: 1008-1018.

Germar EF, Berendt GC (1856) Die im Bernstein befindlichen Hemipteren und Orthopteren der Vorwelt. In: Berendt GC (Ed) Die im Bernstein befindlichen organischen Reste der Vorwelt, 2(1). Berlin, ii+1-40.

Logvinenko VN (1975) Planthoppers. Fulgoroidea. Fauna Ukraini 20(2). Naukova dumka, Kiev, 288 pp. [in Ukrainian]

McPherson KR, Wilson SW (1995) Life history and descriptions of immatures of the dictyopharid planthopper Phylloscelis pallescens (Homoptera: Fulgoroidea). Journal of the New York Entomological Society 103: 170-179.

Metcalf ZP, Wade V (1966) A Catalogue of the Fossil Homoptera (Homoptera: Auchenorrhyncha). General Catalogue of the Homoptera (North Carolina State University, Raleigh), Supplement to Fascicle I: i-iv, 1-245.

Perkovsky EE, Bogdasarov MA (2009) New finds of insects and plants in amber from Belarus. Kharkov Entomological Society Gazette 16: 7-13 [in Russian]

Perkovsky EE, Zosimovich VYu, Vlaskin AP (2010) Rovno amber. In: Penney D (Ed) Biodiversity of Fossils in Amber from the Major World Deposits. Manchester, Siri Scientific Press, 116-136.

Sirrine FA, Fulton BB (1914) The cranberry toad-bug. Bulletin of the New York State Agricultural Experiment Station 377: 91-112.

Szwedo J (2008) A new tribe of Dictyopharidae planthoppers from Eocene Baltic amber (Hemiptera: Fulgoromorpha: Fulgoroidea), with a brief review of the fossil record of the family. Palaeodiversity 1: 75-85.

Szwedo J, Bourgoin Th, Lefebvre F (2004) Fossil Planthoppers (Hemiptera: Fulgoromorpha) of the World. An Annotated Catalogue with Notes on Hemiptera Classification. Studio 1, Warsaw, 200 pp.

Urban JM, Cryan JR (2009) Entomologically famous, evolutionarily unexplored: The first phylogeny of the lanternfly family Fulgoridae (Insecta: Hemiptera: Fulgoroidea). Molecular Phylogenetics and Evolution 50: 471-484.

Weitschat W, Wichard W (1998) Atlas der Pflanzen und Tiere im Baltischen Bernstein. Pfeil, München, $260 \mathrm{pp}$.

Wilson SW, McPherson JE (1981) Notes on the biology of Nersia florens (Homoptera: Fulgoroidea: Dictyopharidae) with descriptions of eggs, and first, second, and fifth instars. The Great Lakes Entomologist 14: 45-48.

Wilson SW, Wheeler AG (1992) Host plant and descriptions of nymphs of the planthopper Rhabdocephala brunnea (Homoptera: Fulgoridae). Annals of the Entomological Society of America 85: 258-264.

Yang Ch-T, Yeh W-B (1994) Nymphs of Fulgoroidea (Homoptera: Auchenorrhyncha) with descriptions of two new species and notes on adults of Dictyopharidae. Chinese Journal of Entomology Special Publication 8: i-iv+1-189. 